\title{
Palliative Care for Non-Cancer Patients in Tertiary Care Hospitals
}

\section{Sonali Sarkar}

\section{Sonali Sarkar}

Dept of PSM, JIPMER, Pondicherry

Correspondence

Dr. Sonali Sarkar,

Department of PSM, JIPMER,

Pondicherry.

Email: sarkarsonaligh@gmail.com

\section{History}

- Submission Date: 06-11-2016;

- Accepted Date: 08-11-2016.

DOI : 10.5530/ijmedph.2016.4.1

Article Available online

http://www.ijmedph.org/v6/i4

\section{Copyright}

(C) 2016 Phcog.Net. This is an openaccess article distributed under the terms of the Creative Commons Attribution 4.0 International license.

\section{Non-cancer conditions and palliative care}

In the recent times medical fraternity has realized the limitations of curative medicine in improving the quality of life of patients suffering from chronic diseases and importance of palliative medicine in caring for these patients. Palliative care is now recognized as the need of not only cancer patients but also people with HIV, severe kidney disease, heart failure, end stage lung disease, progressive neurological diseases and other life limiting illnesses. ${ }^{1}$ In 2010 the major contributions to diseases requiring palliative care in India were from non-communicable diseases that accounted for $53 \%$ of all deaths. Among them, cancers constituted only $6 \%$, whereas cardiovascular diseases contributed to $24 \%$ followed by respiratory diseases (11\%), injuries (10\%) and diabetes $(2 \%) .{ }^{2}$ As per the Global Atlas of Palliative care, the common conditions among adults and children which require palliative care are given in table no 1 . The less common conditions are multidrug-resistant tuberculosis $(0.8 \%)$, Parkinson's disease $(0.48 \%)$, rheumatoid arthritis $(0.27 \%)$ and multiple sclerosis $(0.04 \%)$ among adults and cardiovascular diseases $(6.18 \%)$, endocrine and blood immune disorders (5.85\%), cancer (5.69\%), neurological conditions (2.31\%), kidney diseases (2.25\%), cirrhosis of liver (1.06\%) among children. ${ }^{3}$

Cancer ranks second among adults and eighth among the children. People with non-cancer life limiting diseases also suffer from physical symptoms like pain and psychosocial distress which compromises their quality of life very often for the rest of their lives, affecting also the family members and caregivers. Palliative care as defined by $\mathrm{WHO}^{3}$ is the solution to these patients given that curative medicine is focused on biomedical mechanisms alone.

\section{Need and availability of palliative care for non-cancer conditions}

The need of palliative care among cancer patients in India is largely unmet. But that does not and should not overshadow the needs of other non-cancer patients. One of the fundamental texts on the subject, the Oxford Textbook of Palliative Medicine (Doyle, Hanks, \& MacDonald, 1993), cites several reasons for the fact that most palliative programs offer care mainly to cancer patients and their families. ${ }^{4}$ But, Sandra McKinnon about her experience of what happens to people dying of non-cancer diagnosis states in her article that even though the illness may eventually lead to death, people will live, on average, much lon- ger with any medical diagnosis other than cancer. ${ }^{4}$ In the same article, the author questions, "how is chronic cancer any different from chronic liver failure, chronic renal disease, or chronic respiratory diseases, how does the lived experience of people with these various diagnoses differ from each other?" She justifies the need of palliative care services for non-cancer patients stating that each of these illnesses is characterized by exacerbations and remissions with an eventual terminal phase requiring support for patients and families. The support required by people dying from any of the medical condition is not different from the support needed by someone dying from cancer. ${ }^{4}$ In a review of 14 studies Luddington $\mathrm{L}$ et al also summarized that some patients dying of non-cancer conditions have needs comparable with those dying of cancer. ${ }^{5}$

The right to a pain free and dignified life cannot be denied to people suffering from conditions considered less serious than cancer. Especially when the numbers of such chronic non-communicable diseases are on an increasing trend in India. Nearly 3.6 crore cases of coronary heart disease and 3.1 crore cases of diabetes was estimated for the year 2005 and was expected to have risen to nearly 6.1 crore and 4.6 crore cases respectively in 2015 . Hypertension prevalence among adults $\geq 20$ years was 159.46 per thousand. In addition to these non-communicable diseases, wide availability of anti-retro viral therapy has made HIV to be a chronic condition requiring palliative care; around 2.7 million people are living with HIV and about 1.89 million suffer from pain requiring palliative care. ${ }^{6}$ The need for palliative care is further increased in India because of rising life expectancy and increasing proportion of elderly in the population. ${ }^{6}$ It is known that only less than $2 \%$ of those who need have access to any type of palliative care in India ${ }^{7}$ given that the total number who need palliative care is estimated to be 6 million people a year. ${ }^{8}$ In India currently about 908 palliative care centres are providing palliative care either through home care or on outpatient basis or in-patient service. Among them 841 centres are in Kerala. Majority of the palliative care services are available only in one state and there are some states in the country without a single centre providing palliative care services. ${ }^{6}$ Globally this new millennium has seen a growth of $138 \%$ in palliative care teams made available in hospital settings. ${ }^{9}$ But, these resources are unequally distributed, with the western countries having a higher concentration of these resources. As noted by Prof. Sushma Bhatnagar, there is still inadequate access to palliative care by people suffering from noncancer chronic ailments. ${ }^{10}$ Having said that 
the number of people requiring palliative care for non-cancer conditions in India is huge and such care has to be provided in conjunction with the standard treatment they receive, the question that arises is, where and how can these services be planned and offered. Institution-based models of palliative care have not been considered as realistic solutions even in global scenario and more so in India keeping in mind the numbers and the lack of facilities in the hospitals. Community based palliative care programmes have been developed and are running successfully through the Neighbourhood Network of Palliative Care (NNP) units in Kerala. But the same has not been possible in the rest of the country, as it requires unique standards of community participation in providing and managing palliative care services. Without the awareness, motivation and empowerment of the communities, it is difficult to replicate the Kerala model in rest of the country. Till the time such an emancipation and realization of the population happens so as to have ownership and take active role in management of the programme, palliative care needs of the non-cancer patients cannot be ignored.

\section{The way forward}

Therefore the next question that arises is how can palliative care be integrated with the routine management of these non-cancer conditions. The guiding principles as rightly suggested by the Expert Group for the Proposal of Strategies for Palliative Care in India is to deliver palliative care at all levels of the health delivery systems, from primary to tertiary levels. ${ }^{6}$ The Global Atlas has described Palliative care to be provided at three different levels: i) through a 'palliative care approach' adopted by all healthcare professionals, provided they are educated and skilled through appropriate training ii) 'general palliative care' provided by primary care professionals and those treating patients with life-threatening diseases, with a good basic knowledge of palliative care, and iii) 'specialist palliative care' provided by specialized teams for patients with complex problems. ${ }^{3}$

Primary care providers are less equipped to manage all these conditions and therefore most of these ailments are treated either at the secondary or tertiary level hospitals. Most conditions that have been recognized to be requiring palliative care are at some time point in the course of the illness, treated in tertiary care set-ups. Though the exact figures are not available, a high proportion of deaths in India occur in hospitals.

Experts have put forth the argument for specialist training in palliative medicine and it was expressed that a body of specialists trained in palliative medicine would help India to influence national level policy making, involve the policy makers and ensure political will and backing to implement palliative care as per $\mathrm{WHO}$ vision and mission statement. ${ }^{11}$ It is also important to note that based on the feasibility of operationalization of the strategies, short-, mid- and long-term goals should be set. With the huge number of patients requiring palliative care in India, the number of specialist required will be equally colossal. Presently the awareness among the medical graduates regarding palliative care is as low as $41.6 \% \cdot{ }^{12}$ In addition to having specialists we also need to train our medical graduates and postgraduates in the basic principles of providing palliative care so that palliative care can be integrated with the routine management and specialist services can be reserved only for more complicated cases. This recommendation is not new as in the review of the book Palliative Care for Non-Cancer Patients, Weatherall suggested that palliative care must be integrated increasingly into medical education, at both undergraduate and postgraduate level. He further states "considering the diversity of skills required and the increasing workload, the care of the terminally ill, and certainly the chronically ill, will for the most part have to remain within individual hospital specialties, the community and the family.".
Table 1: Common diseases requiring palliative care among adults and children

\begin{tabular}{ccc}
\hline \multicolumn{2}{c}{ Common diseases requiring palliative care } & Proportion (\%) \\
\hline & Cardiovascular diseases & 38.5 \\
Cancer & 34 \\
Adults & Chronic respiratory diseases & 10.3 \\
& HIV/AIDS & 5.7 \\
& Diabetes & 4.5 \\
& Kidney diseases & 2.02 \\
& Cirrhosis of the liver & 1.7 \\
Alzheimer's disease and other dementias & 1.65 \\
Children & Congenital anomalies & 25.06 \\
& Neonatal conditions & 14.64 \\
& Protein Energy Malnutrition & 14.12 \\
Meningitis & 12.6 \\
\hline
\end{tabular}

To improve the scenario and for successfully implementing the first of the three strategies given by Global Atlas i.e. 'palliative care approach' for all healthcare professionals, all doctors and nurses have to be trained in skills of delivering palliative care services. If such training is given, the second strategy of 'general palliative care' can also happen. This can happen only when it is introduced as a must-know area into the graduate curriculum for medical and nursing courses. In the Proposal of Strategies for Palliative Care in India, the recommendations for tertiary care centres focus on providing palliative care to mainly cancer patients in the Tertiary Cancer Centres (TCC) Scheme. ${ }^{4}$ But tertiary care centres can be a good point of access to all non-cancer patients requiring palliative care and if the treating physicians and nurses are oriented and skilled to provide palliative care, the outcomes of treatment can improve. The care can be part of the continuum that the patients would receive also in the community. So when planning for the palliative care services in the country through integration into the public health, the oft neglected non-cancer diseases should remain in focus of our policy makers and the large network of tertiary hospitals should also be in the service delivery of palliative care.

\section{REFERENCES}

1. Palliative Care Toolkit Improving care from the roots up in resource-limited settings [Internet]. Worldwide Palliative Care Alliance; 2008 [cited 2016 Nov 3]. Available from: www.thewpca.org/EasySiteWeb/GatewayLink.aspx?alld=6147

2. Non-communicable Diseases Country Profiles 2011 [Internet]. World Health Organization; 2011 [Cited 2016 Nov 3]. Available from: http://whqlibdoc.who.int/ publications/2011/9789241502283_eng.pdf

3. Worldwide palliative care alliance. Global Atlas of Palliative Care at the End of Life [Internet]. World Health Organization; 2014 p. 111 [cited 2016 Nov 3]. Available from: www.who.int/nmh/Global_Atlas_of_Palliative_Care.pdf

4. McKinnon S. Palliative Care: Just for Cancer Patients? [cited 2016 Nov 3]. Available from: palliative.org/NewPC/_pdfs/editorial/other/PalliativeCare_justcancerpatients.pdf

5. Luddington L, Cox S, Higginson I, Livesley B. The need for palliative care for patients with non-cancer diseases: a review of the evidence. Int J Palliat Nurs. $2001 ; 7(5): 221-6$

6. Proposal of Strategies for Palliative Care in India (Expert group report) [Internet] Directorate General of Health Services Ministry of Health \& Family Welfare; 2012 Nov [cited 2016 Nov 3]. Available from: http://palliumindia.org/cms/wpcontent/uploads/2014/01/National-Palliative-Care-Strategy-Nov_2012.pdf

7. Kumar S. Models of delivering palliative and end-of-life care in India. Curr Opin Support Palliat Care. 2013;7(2):216-22.

8. Patel F, Sharma S, Khosla D. Palliative care in India: Current progress and future needs. Indian J Palliat Care. 2012;18(3):149.

9. Palliative care in hospitals continues rapid growth for 10th straight year, ac- 
cording to latest analysis. Center to Advance Palliative Care website. [Last accessed on 2016 Nov 3]. Available from: http://www.capc.org/news.and.events/ releases/071411.

10. Bhatnagar S, Gupta M. Future of Palliative Medicine. Indian J Palliat Care. 2015;21(1):95-104

11. Adhinarayanan S. Specialty training in Palliative Medicine - Need of the hour. Int J Med Public Health. 2016; 6(3):109-110.
12. Giri PA, Phalke DB. Knowledge regarding palliative care amongst medical and dental postgraduate students of medical university in western Maharashtra, India. CHRISMED J Health Res. 2014;1(4):250-3.

13. Weatherall DJ. Book of the month-Palliative Care for Non-Cancer Patients. Journal of The Royal Society of Medicine. 2001;94(11):600-1.

Cite this article : Sarkar S. Palliative Care for Non-Cancer Patients in Tertiary Care Hospitals. Int J Med. Public Health. 2016;6(4):151-3. 